\title{
Application of the Blended-teaching Mode of Logistics Management in Higher Vocational Colleges
}

\author{
Teng Han \\ Jiangsu College of Finance and Accounting, Lianyungang City, Jiangsu \\ Province, 222061, China
}

\begin{abstract}
As a new theoretical system and teaching mode, blended-teaching can enrich the teaching form, and it can not only play teachers' leading role, but also can well reflect the students' initiative, active and creative ability. It is bound to have a profound impact on the traditional teaching mode of logistics management in to actively explore the application of blended teaching mode in the logistics management in Higher Vocational Colleges. Based on the author's learning and practical experience, this paper first analyzed the theoretical basis of blendedteaching, then constructed a blended-teaching mode of logistics management in Higher Vocational Colleges, finally put forward a further thought about the blended-teaching mode.

Keywords: Blended-teaching; Teaching mode; Higher vocational colleges; Logistics management; Application
\end{abstract}

\section{Introduction}

Whether the teaching mode is scientific and reasonable directly restricts the effect of teaching and affects the quality of personnel training. The monotonous of teaching mode is the main problem of the current university teaching. In teaching practice, teachers are still the center, and students are only passive receivers of knowledge, which is not conducive to the cultivation of innovative talents. Through a variety of collaborative learning platform support, we can get rid of the shackles of the traditional teaching mode of knowledge learning in the form 
of cooperative learning, therefore, students can learn the most essential knowledge, at the same time, teachers can also cultivate students' ability of analysis, judgment and integration, and enhance students' critical thinking[1].

\section{The Theoretical Basis of Blended-teaching}

Blended-teaching concept is based on the theory of blended learning, so it is of great significance to fully understand the theory of blended learning in the construction of blended teaching model. Blended-learning is to combine the advantages of traditional teaching and E-Learning to fully reflects the initiative, enthusiasm and creativity of students. Only by the combination of the two methods, can the advantages of them get the best learning results. Blended learning is a new way of training in order to achieve a certain teaching objectives and achieve good learning or work results. It is combined with Web technology, or combined with a variety of teaching methods and teaching technology learning process. Blended learning is a side of blended teaching, which focuses on students' learning. The traditional face-to-face teaching and online teaching can take a organic integration for blended teaching includes "teaching" and "learning". Its core idea is to emphasize the guiding role of teachers and students' autonomous learning, emphasize the combination of classroom teaching and online learning environment, emphasizing the effective use of different teaching resources and teaching media, so as to improve the effect of "teaching" and "learning"[2].

\section{The Blended-teaching Mode of Logistics Management in Higher Vocational Colleges}

Blended-teaching Mode is a flexible and diversified teaching mode based on the theory of Cooperative Teaching. Based on the theme of the project, a number of teaching professional communities, it is composed of a group of teachers and a group of enterprises. It is a way to change the habits and roles of teachers in the traditional teaching mode. In the "teaching", it is composed of different expertise of teachers group, so it can make full use of the expertise of teachers to work in cooperation with a due division of labor and carry on the multiple, effective teaching. In the aspects of "learning", teachers of teaching group design a variety of lively courses based on individual differences by professional interaction and dialogue, to fully meet the needs of students[3]. Based on the objectives and characteristics of logistics management training and combined with the meaning and characteristics of the blended-teaching, we can construct a blended-teaching mode with one project theme, two learning platforms, three types of participants, four evaluation subjects, centered on the theme of the project. Build two learning platform, through a variety of ways to work together to establish a multi teaching evaluation mechanism, as shown in figure 1: 


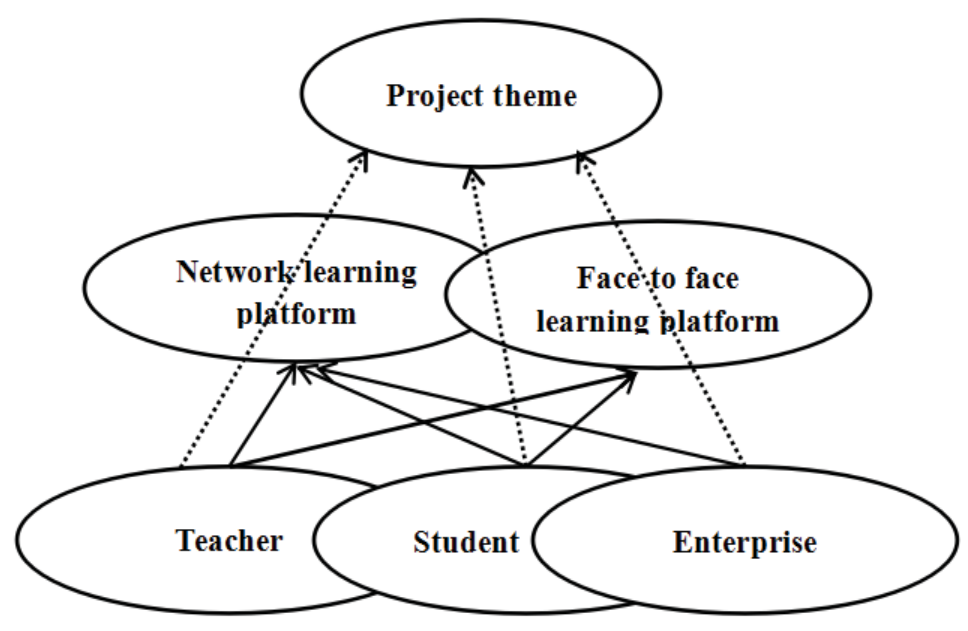

Fig.1 Mixed mode of logistics management major

\subsection{Project theme oriented}

Project topics is the combination of enterprise groups with their own characteristics. Practice project provider publishes their design needs and rewards to the online learning platform, and the group of teachers choose the course according to the teaching content, and then student groups enter the appropriate modules according to their learning progress and interest. They challenge different design tasks, and they can communicate with the project provider during the period. Students can also consult the professional teacher group to t obtain the appropriate professional guidance, until the submission and completion of design tasks or solve practical problems[4].

\subsection{Major communities in teaching and learning}

The teaching community in the model contains teacher group, enterprise group and student community. The most important feature of collaborative teaching is the teacher's complementary expertise. Because the teacher's expertise is limited, and often need to take more than two subjects at the same time. Based on the theme of a project, teachers of different expertise can work together to develop a collaborative plan. In the group interaction, teachers can continue to discuss the teaching content and teaching plan. In the actual teaching, teachers teach students with the same learning stages and levels based on each teacher's own subject and familiar teaching methods[5]. Enterprise group is mainly to establish the social selection of library according to the actual situation of enterprises. 


\subsection{Flexible teaching model}

Because the blended-teaching is a professional combination of teachers with different majors, the teaching group of teachers adopt different teaching methods, such as class teaching, group discussion or independent study in different teaching methods in order to get the best teaching effect. It can also be a combination of different specialties, such as a single field of collaborative, multidisciplinary field synergy, cyclic coordination. According to the curriculum design and the teachers' expertise, it presents the flexible and diversified teaching contents.

The construction of the two learning platform. To establish a face to face teaching platform and online learning platform. Situational teaching platform is mainly based on the situation of "face to face" learning. According to the needs of the selected theme, many teachers carry out curriculum content design and organization of teaching. At the same time, it needs to set up the corresponding scene and different student communities, to achieve the purpose of teaching through the interaction between teachers and students. Online learning platform is mainly for students to speak freely through cyberspace, discussion and communication, to achieve mutual promotion effect. According to their learning progress and interest, students can get into the corresponding project theme module to challenge the different design tasks, and during this period, they can further communicate with the project provider by the network.

\section{A Further Thought about the Blended-teaching Mode}

First, how to enhance the effectiveness of the use of Bb platform? Lower connection speed has been one of the main reasons hindering the popularization of $\mathrm{Bb}$ platform application. The function of the forum, the function of investigation, the evaluation function of the group, and the statistical function of the course need to be further improved. In addition, it is necessary to carry out the research and use of personalized function utilization[6].

Second, how to strengthen the guidance of students? Most of the students said that they need guidance on network learning before and after school, which requires relevant departments of education and technical schools to give the methods and skills of learning more targeted guidance and training.

Third, how to better construct knowledge? Blended-teaching involves large and complex knowledge content, so it needs teachers and students to grasp and choose the content, especially for the curriculum with a variety of attributes. How to classify knowledge construction is especially important. According to the situation that the learning materials provided by the teachers do not match with the prior knowledge of the students, "Logistics" network assisted instruction takes the method of basic version + special version to provide the corresponding curriculum documents, learning materials to guide the use of exchange and discussion area for different classes of teaching needs. 
Fourth, how to strengthen the emotional interaction? The blended-teaching mode should combine the advantages of traditional teaching and network teaching to play the biggest complementary effect. At present, due to the limitation of time, energy and incentive mechanism, there is a lack of face-to-face communication between teachers and students. The online forum discussion is not enough, and there are still many "divers" who just wait and don't speak. How to guide "diver", how to pay attention to the student's interest in the topic of discussion, thinking and communication, are some important questions for the teacher to strengthen emotional interaction.

Fifth, how to optimize the learning evaluation? The blended teaching mode of this course is based on the three-dimensional evaluation system, and judging from the current effect, this can be achieved through the Blackboard platform, but it is limited and lacks a reasonable design and optimization[7]. How to evaluate the degree of participation and contribution of students' network learning, how to realize the real time evaluation of login or participation, and how to increase the group learning evaluation need the platform company, cooperation center of educational technology and classroom teachers to achieve it.

\section{Acknowledgement}

The research was supported by Jiangsu Province Institute of higher education, higher education and scientific research project of "13th Five-Year" - Research and practice on construction way of quality resources sharing class for Logistics Specialty of high vocational college under blended learning.

\section{References}

[1Liu Yanxia. The application of hybrid network teaching method in the teaching reform of Vocational Colleges. National Training, (22), pp.206-208, 2016.

[2] Shi Chengdong, Li Hui, Sun Liyuan. Research on the blended learning model of international logistics. Value engineering, (26), pp.249-250, 2016.

[3] Hu Yiqin. A study on the effectiveness of blended learning in public English Teaching in Higher Vocational Colleges. Journal of Guangxi Normal University for Nationalities, (01), pp.138-140, 2016.

[4] Li Rong, Zhou Weibai. The application of mixed creative teaching method in VB programming. Computer Times, (04), pp.47-48, 2014.

[5] Hu Meiyan. Based on blended learning research and practice of teaching. Education, (23), pp.276-277, 2013.

[6] Su Lingling. The application of blended learning concept in e-commerce. Journal of Yuncheng University, (04), pp.74-76, 2010.

[7] Zhang Xiaoyan. Teaching reform of logistics management specialty in Higher Vocational Colleges. Journal of Liaoning Administration College, (05), pp.89-90, 2008. 